\title{
Metabolismo oxidativo e cardíaco de equinos submetidos a exercício de baixa intensidade antes e após suplementação com antioxidante
}

\section{Oxidative and cardiac metabolism of horses subjected to low intensity exercise before and after antioxidant supplementation}

\author{
Letícia Andreza Yonezawa ${ }^{\mathrm{I}}$ Tatiana de Sousa Barbosa ${ }^{\mathrm{II}}$ Marcos Jun Watanabe ${ }^{\mathrm{III}}$ \\ Jhônatas Luiz Knaut ${ }^{\mathrm{III}}$ Camila Luz MarinhoIII Lilian Emy dos Santos Michima ${ }^{\mathrm{IV}}$ \\ Aguemi KohayagawaII
}

\section{RESUMO}

O presente estudo objetivou avaliar os marcadores cardíacos e de lipoperoxidação em equinos no teste de exercício de baixa intensidade e longa duração (TLD), antes e após a suplementação com vitamina E. Para tanto, foram utilizados 10 equinos, submetendo-os ao primeiro TLD, com carga de trabalho fundamentada no consumo máximo de oxigênio individual $\left(V O_{2 m a}\right)$. Em seguida, durante 59 dias, os equinos receberam vitamina $E$ (dl-alfa-tocoferol) na dose diária de $1.000 U I$ por via oral e, posteriormente, realizaram um segundo TLD com o mesmo protocolo do primeiro. As amostras de sangue foram colhidas para determinação do malondialdeído (MDA) plasmático, como índice de lipoperoxidação, da concentração sérica de troponina I cardíaca (cTnI) e da isoenzima MB da creatinoquinase (CK$\mathrm{MB})$ como marcadores cardíacos. Como efeito do exercício, não se observou aumento significativo de MDA nem de cTnI, mas sim da concentração sérica de CK-MB, sugerindo-se o estresse miocárdico. A suplementação foi capaz de amenizar a produção de espécies reativas de oxigênio, evidenciada pela menor concentração de MDA em todos os momentos avaliados, porém não causou efeito protetor no miocárdio. Concluiu-se que o exercício de baixa intensidade e longa duração promoveu estresse miocárdico em equinos de forma leve e a suplementação com vitamina $E$ reduziu a lipoperoxidação.

Palavras-chave: malondialdeído, troponina I cardíaca, CK-MB, vitamina E, fisiologia do exercício, cavalo.

\section{ABSTRACT}

The present study aimed to evaluate cardiac and lipoperoxidation markers in horses subjected to low intensity and long duration (TLD) exercise test, before and after vitamin $E$ supplementation. For this purpose, 10 horses were used, subjecting them to the first TLD with a workload based on individual maximal oxygen uptake $\left(\mathrm{VO}_{2 \operatorname{ma}}\right)$. Then, horses received vitamin $\mathrm{E}$ (dl-alphatocopherol) during 59 days at a daily oral dose of 1,000IU, and thereafter they performed a second TLD with the same protocol as the first. Blood samples were collected to determine plasma malondialdehyde (MDA) as an index of lipoperoxidation, serum cardiac troponin I (CTnI) and creatine kinase MB isoenzyme (CK$M B)$ as cardiac markers. As a result of the exercise, there was no significant increase in MDA or CTnI, but serum CK-MB increased suggesting myocardial stress. The supplementation was able to minimize reactive oxygen species production, as evidenced by lower concentrations of MDA at all times evaluated, but it didn't cause protective effect on the myocardium. It was concluded that the low intensity and long duration exercise promoted light myocardial stress in horses and vitamin E supplementation reduced lipoperoxidation.

Key words: malondialdehyde, cardiac troponin I, CK-MB, vitamin E, exercise physiology, equine.

\section{INTRODUÇÃO}

Os equinos são considerados atletas natos e são participantes de diversos tipos de competições esportivas. Desse modo, há grande preocupação com a queda de desempenho desses animais em decorrência de diversas disfunções orgânicas. Dentre elas, as cardiovasculares são responsáveis por alterações que acarretam, desde uma intolerância ao exercício até a morte súbita e são referidas como a terceira maior causa de queda de desempenho (YONEZAWA et al., 2009).

IDepartamento de Medicina Veterinária (DMV), Centro de Ciências Agroveterinárias (CAV), Universidade do Estado de Santa Catarina (UDESC), Av. Luiz de Camões, 2090, 88520-000, Lages, SC, Brasil. E-mail: leticiay@gmail.com. Autor para correspondência.

IIDepartamento de Clínica Veterinária, Faculdade de Medicina Veterinária e Zootecnia (FMVZ), Universidade Estadual Paulista (Unesp), Campus de Botucatu, Botucatu, SP, Brasil.

IIIDepartamento de Cirurgia e Anestesiologia Veterinária, FMVZ, Unesp, Campus de Botucatu, Botucatu, SP, Brasil.

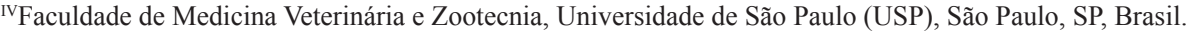


Sabe-se que o exercício físico é capaz de produzir as espécies reativas de oxigênio (ERO) e, uma vez formadas, podem iniciar uma cadeia de reações prejudiciais às membranas celulares, ocasionando lipoperoxidação (WILLIAMS \& CARLUCCI, 2006; YONEZAWA et al., 2010a). As ERO são normalmente formadas como parte do metabolismo celular, mas, quando há o desequilíbrio entre ERO e antioxidantes, estabelece-se o estresse oxidativo, podendo causar considerável dano irreversível às células, determinando lesão ou até mesmo doença (LYKKESFELDT \& SVENDSEN, 2007; KANE, 2009).

No exercício aeróbico, a produção de ATP é a via mais importante e há uma elevação da demanda de oxigênio em relação ao estado de repouso, com aumento do consumo de oxigênio pela mitocôndria e do fluxo de elétrons através da cadeia respiratória, ocasionando uma maior produção de ERO (KOSTAROPOULOS et al., 2006). Um estudo em humanos, comparando diversos tipos de intensidade de exercício, observou que a corrida de maratona promoveu estresse oxidativo mais intenso, comparada às atividades de curta e média duração. Sugere-se que a corrida de longa duração poderia conduzir o organismo a uma falta de capacidade em suportar o estresse oxidativo por um longo tempo, mostrando a necessidade de suplementação dietética com antioxidantes (SOUZA JR et al., 2005).

Desse modo, a suplementação com antioxidantes objetiva restabelecer ou manter o equilíbrio oxidante/antioxidante e parece ser uma perspectiva promissora para o bem-estar animal e desempenho atlético. Como a deficiência de antioxidantes, o estresse oxidativo induzido e a consequente intolerância ao exercício físico já foram claramente estabelecidos, o oposto, ou seja, a suplementação de antioxidantes para prevenção de injúrias ou até melhoria do desempenho atlético ainda precisa ser comprovada (YONEZAWA et al., 2010a).

Enquanto uma elevada demanda de oxigênio ocorre no coração durante o exercício físico e consequente demasiada produção de ERO, a capacidade antioxidante parece ser limitada no músculo cardíaco, tornando-o susceptível à lesão tecidual por estresse oxidativo após um período de exercício agudo. Embora haja evidências diretas da ocorrência de estresse oxidativo e de lipoperoxidação, a vitamina E pode promover proteção do coração contra situações deletérias decorrentes do exercício (ASCENSÃO et al., 2003; YONEZAWA et al., 2010a).

Ainda não foi totalmente estabelecido se o exercício físico, tanto de curta como o de longa duração, pode promover lesão cardíaca e por qual mecanismo de ação. Especula-se que a lesão miocárdica possa ocorrer em decorrência de uma isquemia durante o exercício e deva estar associada ao acúmulo de ERO (WHYTE et al., 2000). Adicionalmente, em equinos, parece ser difícil a detecção e quantificação da injúria miocárdica.

Ainda que a prática de exercícios físicos seja amplamente recomendada, a participação em eventos esportivos cada vez mais exaustivos exige o conhecimento da resposta fisiológica cardíaca para a segurança do animal atleta. Portanto, o presente trabalho pretendeu avaliar o efeito fisiológico do exercício e deletério das ERO, sob o ponto de vista bioquímico, nas células musculares cardíacas, por meio da determinação de marcadores cardíacos séricos e de lipoperoxidação, além de verificar o efeito da suplementação com vitamina $\mathrm{E}$ em equinos submetidos ao exercício de baixa intensidade e longa duração em esteira de alta velocidade.

\section{MATERIAL E MÉTODOS}

Utilizaram-se 10 equinos, sendo cinco da raça Puro Sangue Árabe e cinco da raça Crioula, sem treinamento físico por mais de um ano, com idade variando de oito a 10 anos, peso médio de $372,1 \pm 32,9 \mathrm{~kg}$, clinicamente hígidos. Os animais foram mantidos em piquetes, sob as mesmas condições de manejo alimentar e sanitário. O manejo nutricional consistiu de alimentação a base de feno de capim "coast-cross" (Cynodon dactylon), ração comercial para equinos (Royal Horse Sport, Socil, Brasil), suplemento mineral (Equifós, Matsuda, Brasil) e água ad libitum.

Os equinos foram submetidos a um teste padrão de exercício progressivo em esteira de alta velocidade (Mustang 2200 AG, Kagra, Suíça) inclinada a $6 \%$, da qual a velocidade foi elevada gradualmente, com o protocolo de exercício proposto por WATANABE et al. (2009). Utilizou-se a máscara de análise de trocas gasosas e dados ventilatórios (Metavet, Cortex, Alemanha) para se extrair a carga de trabalho para cada equino, com base no consumo máximo de oxigênio $\left(\mathrm{VO}_{2 \max }\right)$, sendo o valor médio dos animais de $110,4 \pm 20,4 \mathrm{~mL} \mathrm{~kg}^{-1} \mathrm{~min}^{-1}$.

Após 14 dias do teste progressivo, os equinos foram submetidos ao primeiro teste de baixa intensidade e longa duração (TLD). $\mathrm{O}$ teste, considerado de exercício predominantemente aeróbico (concentração de lactato inferior a $4 \mathrm{mmol} \mathrm{L}^{-1}$ ), foi realizado com a esteira inclinada a $6 \%$, à velocidade de $35 \%$ do $\mathrm{VO}_{2 \max }$ de cada animal pelo período de 
60min (PRINCE et al., 2002), correspondendo a uma velocidade média de $2,3 \pm 0,5 \mathrm{~m} \mathrm{~s}^{-1}$.

A suplementação da vitamina $\mathrm{E}$ (dl-alfatocoferol) dos animais teve início logo após o teste TLD1, na dose de 1.000UI por animal (NRC, 2007), por meio de cápsulas gelatinosas (E-tabs 1000UI, Sigma Pharma, Hortolândia, Brasil) misturadas a raspas de rapadura, por via oral, diariamente e sem interrupção até o final do experimento. Após 59 dias do início da suplementação, os equinos realizaram o segundo teste (TLD2) com o mesmo protocolo de TLD1. A temperatura e a umidade relativa do ar do salão do Centro de Medicina Esportiva Equina da Unesp de Botucatu, onde os testes foram realizados, variou de 17,0 a $20,6^{\circ} \mathrm{C}$ e 66 a $81 \%$, respectivamente.

As colheitas de sangue foram realizadas nos momentos M0 (antes do exercício), PE (imediatamente após) e 1h, 3h, 6h, 12h e 24h após o término do teste, em tubos contendo ativador da coagulação para obtenção de soro, e tubos com EDTA potássico. O soro e o plasma foram imediatamente separados e congelados a $-80^{\circ} \mathrm{C}$ até serem processados.

Aavaliação de lipoperoxidação foi realizada por meio da determinação de malondialdeído (MDA) plasmático, por cromatografia líquida de alta eficiência (HPLC, Shimadzu Corp., Tóquio, Japão), segundo NIELSEN et al. (1997). O perfil dos marcadores cardíacos foi realizado pelas determinações séricas de troponina I cardíaca (cTnI) e da isoenzima MB da creatinoquinase (CK-MB) por meio de kit comercial (Immulite, Siemens Medical Solutions Diagnostics, Los Angeles, EUA) pelo ensaio imunoenzimático de fase sólida por quimioluminescência.

Realizou-se a análise estatística, inicialmente pela análise descritiva das variáveis e a comparação entre os momentos e provas pela análise de variância, com posterior teste de múltipla amplitude de Tukey em caso de distribuição paramétrica ou teste de Kruskall-Wallis, em caso de distribuição não-paramétrica dos dados. Todas as análises foram consideradas significativas quando $\mathrm{P}<0,05$.

\section{RESULTADOS}

Considerando as raças de equinos utilizadas, não houve diferença estatística entre as variáveis e, assim, os dados estão apresentados em conjunto. O exercício físico não promoveu efeito sobre os valores de MDA plasmáticos, uma vez que não houve diferença significativa entre os momentos em ambas as provas. Entretanto, verificou-se influência da vitamina E sobre a produção de ERO, pela menor concentração de MDA $(\mathrm{P}<0,001)$ em todos os momentos após a suplementação (Tabela 1).
As concentrações de cTnI (Tabela 1) séricas não se alteraram nem durante o exercício nem entre as provas, embora se observe uma clara tendência à elevação de cTnI em 3h em TLD1, mas sem significância. No entanto, observou-se aumento significativo $(\mathrm{P}<0,05)$ dos níveis de CK-MB durante o exercício em TLD1 e TLD2, sendo que o valor máximo ocorreu em $12 \mathrm{~h} \mathrm{em}$ ambas as provas (Tabela 1, Figura 1).

\section{DISCUSSÃO}

O exercício prolongado de enduro promove o estresse oxidativo, sendo avaliado pelo aumento dos níveis de MDA (AL-QUDAH \& ALMAJALI, 2008). Neste experimento, o exercício não causou elevações na concentração de MDA tanto em TLD1 como em TLD2. AL-QUDAH \& ALMAJALI (2008) demonstraram aumento do MDA de $1,56 \pm 0,65 \mathrm{nmol} \mathrm{mL} \mathrm{m}^{-1}$ para $4,58 \mathrm{nmol} \mathrm{mL} \mathrm{mL}^{-1}$ em equinos após completarem $90 \mathrm{~km}$ de uma prova de enduro de $120 \mathrm{~km}$, com variação de temperatura de 15 a $25^{\circ} \mathrm{C}$ e de umidade de 30 a $32 \%$. MARLIN et al. (2002) também encontraram valores aumentados de substâncias reativas ao ácido tiobarbitúrico, que incluem o MDA, após prova de enduro de $140 \mathrm{~km}$, em condições ambientais de 15 a $19^{\circ} \mathrm{C}$ de temperatura e 62 a $88 \%$ de umidade. A temperatura e umidade do salão onde os animais realizaram os testes neste estudo foram próximas das encontradas por MARLIN et al. (2002). Segundo MILLS et al. (1996), o ambiente quente e úmido parece aumentar a lipoperoxidação e exacerbar o estresse oxidativo. A temperatura e umidade amenas do presente estudo possivelmente influenciaram nesse aspecto, ocasionando menor taxa de peroxidação lipídica. Acredita-se ainda que o protocolo experimental e/ou possivelmente o bom condicionamento físico dos animais, embora não fossem treinados, não permitiram demonstrar a evidência clássica de estresse oxidativo.

WILLIAMS et al. (2005) relataram que o fornecimento de uma quantidade média de 2.557UI do antioxidante por dia não estimulou o desempenho atlético, tampouco promoveu a melhoria na saúde e bem-estar de um modo geral em equinos participantes de prova de enduro de $80 \mathrm{~km}$. Em contrapartida, de acordo com os resultados, observou-se nitidamente o efeito benéfico da suplementação com vitamina $\mathrm{E}$ ao diminuir os níveis do marcador de lipoperoxidação.

Segundo ATALAY \& SEN (1999), um episódio de exercício físico agudo pode causar danos oxidativos ao coração. No presente estudo, foi constatado um pequeno aumento da concentração de cTnI em 3 h em TLD1, discretamente acima do 


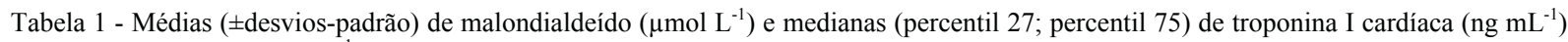
e CK-MB (ng mL ${ }^{-1}$ ) de 10 equinos no teste de baixa intensidade e longa duração (TLD) antes (1) e após a suplementação com vitamina $\mathrm{E}(2)$.

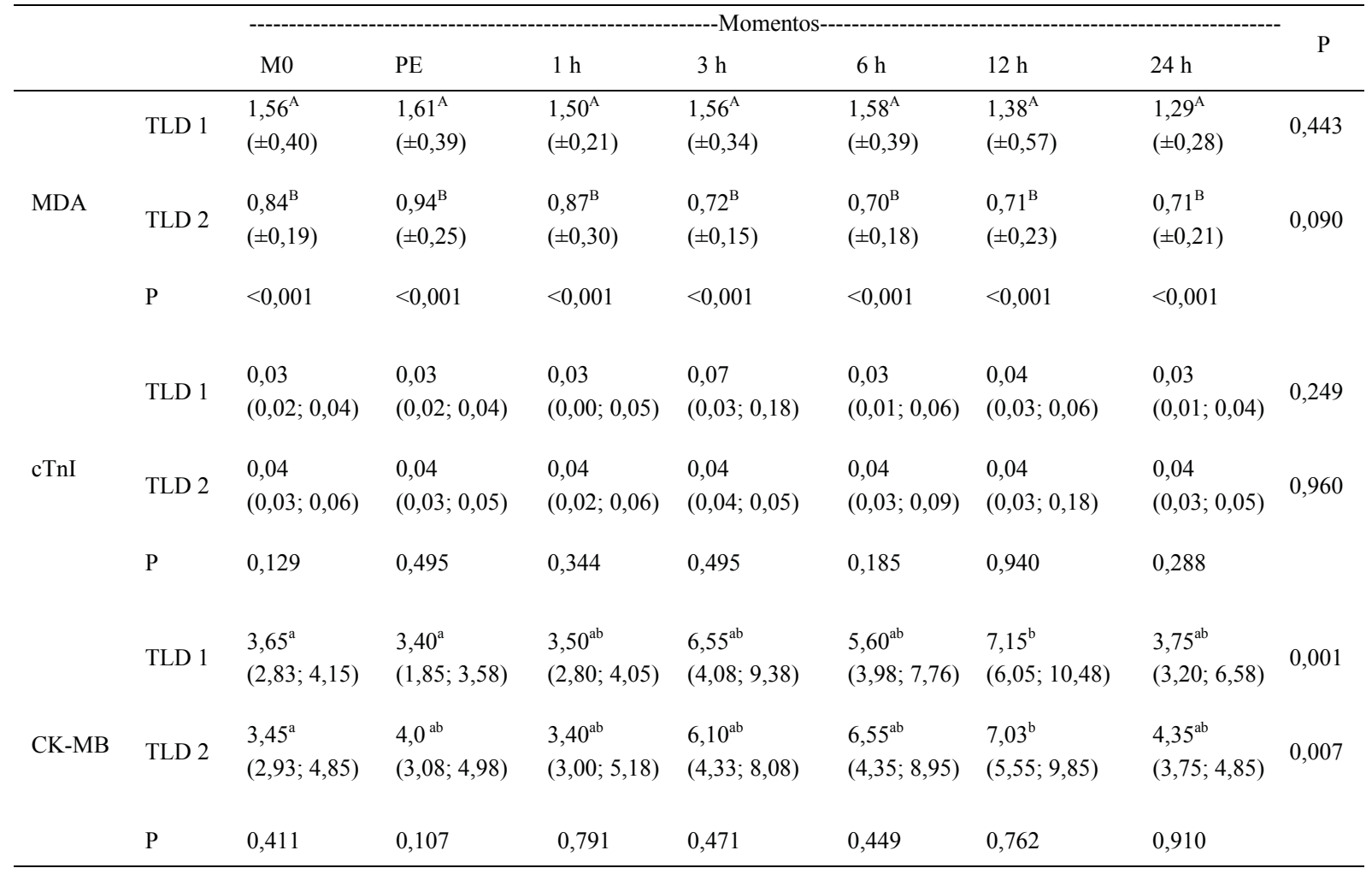

M0: antes do exercício, PE: imediatamente após o exercício, MDA: malondialdeído, cTnI: troponina I cardíaca, CK-MB: isoenzima MB da creatinoquinase.

Letras minúsculas na mesma linha indicam diferença estatística entre momentos.

Letras maiúsculas na mesma coluna indicam diferença estatística entre provas.

limite superior da variação de normalidade descrita por DIVERS et al. (2010) de 0,0 a $0,06 \mathrm{ng} \mathrm{mL}^{-1}$, porém sem significância. MICHIMA et al. (2007) não encontraram elevação do nível de cTnI após provas de enduro de $60,80,120$ e $160 \mathrm{~km}$, mesmo nos animais desqualificados por alterações metabólicas, concluindo que esse tipo de exercício não causa injúrias cardíacas graves. Em desacordo, HOLBROOK et al. (2006) relataram aumento significativo de cTnI após competições de enduro de 80 e $160 \mathrm{~km}$. Os autores não observaram efeito significativo da distância percorrida, da posição de chegada e da velocidade média sobre os valores do marcador, incluindo os animais desqualificados, exceto na prova de $80 \mathrm{~km}$ da qual os animais desqualificados apresentaram maior concentração em relação aos animais que não alcançaram as 10 primeiras colocações. Assim, sugeriram que o exercício de enduro causa certo grau de estresse miocárdico em alguns cavalos, apesar de que os fatores predisponentes associados com o exercício, como o nível de condicionamento físico e o desequilíbrio hidroeletrolítico não foram determinados neste estudo.

Embora os mecanismos de liberação de cTnI induzida pelo exercício ainda não tenham sido totalmente estabelecidos, especula-se que a via principal seja por aumento da permeabilidade dos cardiomiócitos, que libera a troponina dissolvida no citosol celular, causando pequena elevação da proteína na circulação, de maneira reversível e não por uma necrose permanente, como ocorre no infarto do miocárdio (HOLBROOK et al., 2006; YONEZAWA et al., 2010b). Sabe-se que em cães a troponina livre no citosol corresponde de 2 a $8 \%$ do total, sendo que na espécie equina esse valor não é conhecido (YONEZAWA et al., 2010b).

Um fator importante a ser considerado com relação às divergências dos dados na literatura são os diferentes sistemas analisadores que utilizam aminoácidos distintos para composição dos anticorpos 


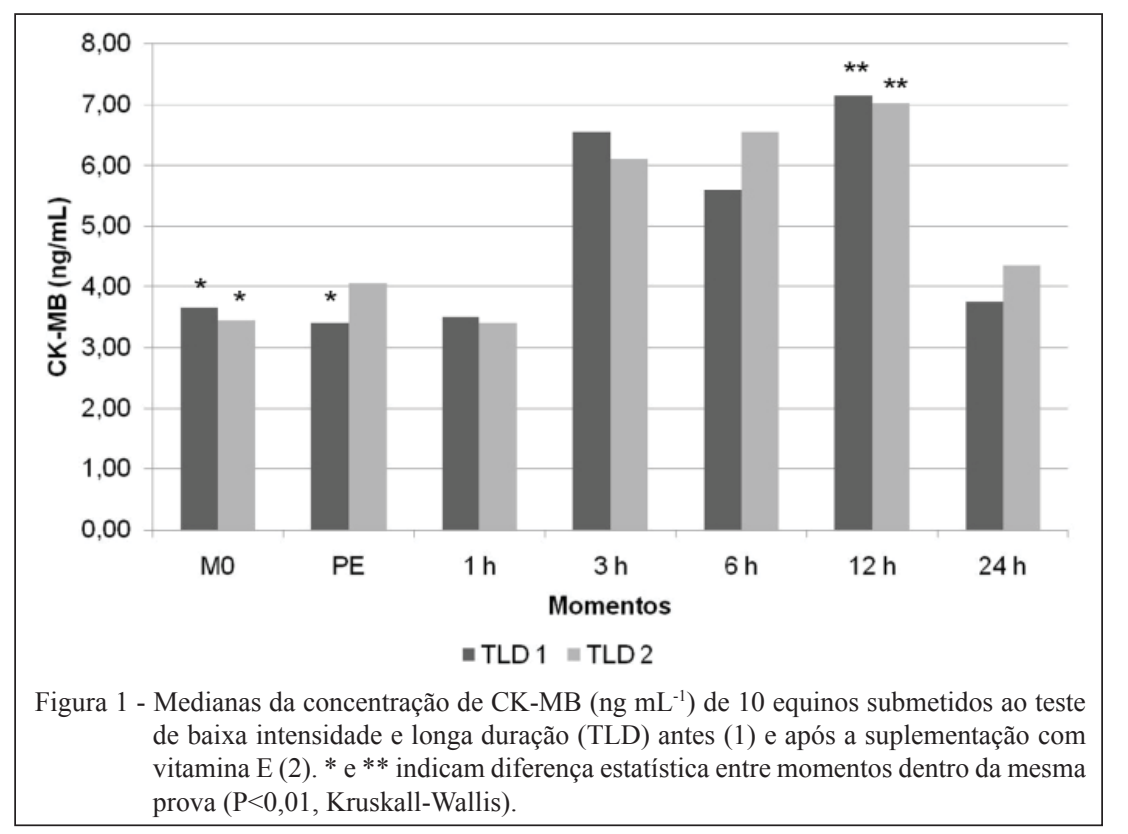

monoclonais. A dificuldade em comparar os dados com os apresentados na literatura se deve a essa divergência de metodologias e tipos de amostragem (YONEZAWA et al., 2010a). Há necessidade de um estudo amplo, comparando os diversos tipos de kits analisadores comerciais para determinação da cTnI na espécie equina, como já realizado para diversas espécies animais, como ratos, cães e macacos (APPLE et al., 2008).

Observou-se aumento da CK-MB em 3h, em ambas as provas, porém somente em $12 \mathrm{~h}$ foi significativamente maior em relação ao M0. Esses dados sugerem que houve um leve estresse miocárdico, mas sem significância clínica aparente. MICHIMA et al. (2010) não verificaram aumento da CK-MB em equinos de enduro, tanto os que finalizaram as provas como os desqualificados por causa metabólica ou claudicação. Os autores acreditam que a utilização da CK-MB como único marcador cardíaco não traz informações relevantes a respeito da integridade cardíaca sob influência do exercício. Neste estudo, o aumento de CK-MB foi acompanhado pela pequena elevação de cTnI, embora tenha ocorrido somente em TLD1, sugerindo o estresse miocárdico. Não foi evidenciado o efeito protetor da vitamina $\mathrm{E}$ sobre o miocárdio, uma vez que os níveis tanto de cTnI como de CK-MB não se alteraram após a suplementação.

\section{CONCLUSÃO}

A partir dos resultados do presente estudo, foi possível concluir que o exercício de baixa intensidade e longa duração promoveu um estresse miocárdico em equinos, evidenciado pelo aumento de CK-MB considerado leve. Verificou-se também o efeito benéfico da suplementação da vitamina $\mathrm{E}$ pela diminuição da concentração de MDA plasmática em todos os momentos avaliados, porém não houve influência do antioxidante sobre miocárdio.

\section{AGRADECIMENTO}

Os autores agradecem à Fundação de Amparo à Pesquisa do Estado de São Paulo (FAPESP), pelo subsídio financeiro para a realização deste estudo.

\section{COMITÊ DE ÉTICA E BIOSSEGURANÇA}

O presente estudo foi aprovado pela Câmara de Ética em Experimentação Animal (protocolo no 188/2007-CEEA) da Faculdade de Medicina Veterinária e Zootecnia, da Universidade Estadual Paulista, Campus de Botucatu.

\section{REFERÊNCIAS}

AL-QUDAH, K.M.; AL-MAJALI, A.M. Higher lipid peroxidation indices in horses eliminated from endurance race because of synchronous diaphragmatic flutter (thumps). Journal of Equine Veterinary Science, v.28, n.10, p.573-578, 2008. Disponível em: <http:/www.sciencedirect.com/science/article/pii/ S0737080608002803>. Acesso em: 07 jan. 2010. doi: 10.1016/j. jevs.2008.08.007.

APPLE, F.S. et al. Analytical characteristics of commercial cardiac troponin I and $\mathrm{T}$ immunoassays in serum from rats, dogs, and monkeys with induced acute myocardial injury. Clinical Chemistry, v.54, n.12, p.1982-1989, 2008. Disponível em: $<$ http://www.clinchem.org/content/54/12/1982.long $>$. Acesso em: 07 jan. 2010. doi: 10.1373/clinchem.2007.097568. 
ASCENSÃO, A. et al. Exercício e stress oxidativo cardíaco. Revista Portuguesa de Cardiologia, v.22, n.5, p.651-678, 2003.

ATALAY, M.; SEN, C.K. Physical exercise and antioxidant defenses in the heart. Annals of New York Academy of Sciences, v.874, n.1, p.169-177, 1999. Disponível em: <http://onlinelibrary. wiley.com/doi/10.1111/j.1749-6632.1999.tb09234.x/pdf>. Acesso em: 07 jan. 2010. doi: 10.1111/j.1749-6632.1999.tb09234.x.

DIVERS, T.J. et al. Measurement and clinical use of cardiac troponin I (cTnI) in horses. In: ANNUAL CONVENTION OF THE AMERICAN ASSOCIATION OF EQUINE PRACTITIONERS, 56., 2010, Baltimore, EUA. Proceedings... Baltimore: AAEP, 2010. Disponível em: <http://www.ivis.org/proceedings/ aaep/2010/z9100110000277.pdf >. Acesso em: 07 jan. 2011.

HOLBROOK, T.C. et al. Endurance exercise is associated with increased plasma cardiac troponin I in horses. Equine Veterinary Journal, v.36, suppl, p.27-31, 2006.

KANE, E.D. Vitamin E: an essential nutrient for horses? Advances in Equine Nutrition, v.4, p.73-85, 2009. Disponível em: <http://www.ker.com/library/proceedings/04/VitaminE_p73. pdf $>$. Acesso em: 07 jan. 2010

KOSTAROPOULOS, I.A. et al. Comparison of the blood redox status between long-distance and short-distance runners. Physiological Research, v.55, n.6, p.611-616, 2006. Disponível em: <http://www.biomed.cas.cz/physiolres/pdf/55/55_611.pdf >. Acesso em: 07 jan. 2011

LYKKESFELDT, J.; SVENDSEN, O. Oxidants and antioxidants in disease: oxidative stress in farm animals. Veterinary Journal, v.173, n.3, p.502-511, 2007. Disponível em: <http://www. sciencedirect.com/science/article/pii/S1090023306001316>. Acesso em: 07 jan. 2011. doi:10.1016/j.tvj1.2006.06.005.

MARLIN, D.J. et al. Changes in circulatory antioxidant status in horses during prolonged exercise. Journal of Nutrition, v.132, p.1622S-1627S, 2002. Disponível em: <http://jn.nutrition.org/ content/132/6/1622S.long>. Acesso em: 07 jan. 2010.

MICHIMA, L.E.S. et al. Estudo da isoenzima creatina quinase CKMB sérica em equinos de enduro após exercício físico prolongado. Brazilian Journal of Veterinary Research and Animal Science, v.47, n.1, p.23-30, (2010). Disponível em: $<$ http://www.revistas.usp.br/bjvras/article/view/26845>. Acesso em: 07 jan. 2011.

MICHIMA, L.E.S. et al. Influência do exercício físico prolongado nos valores séricos de troponina I cardíaca em cavalos de enduro. In: CONFERÊNCIA ANUAL DA ABRAVEQ, 8., 2007, São Paulo, SP. Anais... São Paulo: ABRAVEQ, 2007. Disponível em: <http://www.abraveq.com.br/artigos_viiiconferencia2007/ arquivo58.pdf. $>$. Acesso em: 07 jan. 2011.

MILLS, P.C. et al. Effects of exercise intensity and environmental stress on indices of oxidative stress and iron homeostasis during exercise in the horse. European Journal of Applied Physiology and Occupational Physiology, v.74, p.60-66, 1996.
NIELSEN, F. et al. Plasma malondialdehyde as biomarker for oxidative stress: reference interval and effects of life-style factors. Clinical Chemistry, v.43, p.1209-1214, 1997. Disponível em: $<$ http://www.clinchem.org/content/43/7/1209.long $>$. Acesso em: 07 jan. 2010.

NUTRIENT REQUIREMENTS OF HORSES. 6.ed. 2007. Disponível em: <http://nrc88.nas.edu/nrh/>. Acesso em: 07 jan. 2011.

PRINCE, A. et al. Comparison of the metabolic responses of trained Arabians and Thoroughbreds during high- and low-intensity exercise. Equine Veterinary Journal, v.34, suppl, p.95-99, 2002.

SOUZA JR, T.P. et al. Exercício físico e estresse oxidativo. Efeitos do exercício físico intenso sobre a quimioluminescência urinária e malondialdeído plasmático. Revista Brasileira de Medicina do Esporte, v.11, n.1, p.91-96, 2005. Disponível em: <http://www. scielo.br/pdf/rbme/v11n1/24110.pdf>. Acesso em: 07 jan. 2011.

WATANABE, M.J. et al. Aplicação da espirometria durante teste padrão de exercício progressivo em esteira para avaliação da troca gasosa respiratória de equinos da raça Árabe. Archives of Veterinary Science, v.14, n.1, p.17-24, 2009. Disponível em: $\quad<$ http://ojs.c3sl.ufpr.br/ojs2/index.php/veterinary/article/ view/12848/10716>. Acesso em: 07 jan. 2011.

WHYTE, G.P. et al. Cardiac fatigue following prolonged endurance exercise of differing distances. Medicine and Science in Sports and Exercise, v.32, n.6, p.1067-1072, 2000.

WILLIAMS, C.A.; CARLUCCI, S.A. Oral vitamin E supplementation on oxidative stress, vitamin $\mathrm{E}$ and antioxidant status in intensely exercised horses. Equine Veterinary Journal, v.36, suppl, p.617-621, 2006.

WILLIAMS, C.A. et al. Vitamin E intake and systemic antioxidant status in competitive endurance horses. Equine and Comparative Exercise Physiology, v.2, p.149-152, 2005. Disponível em: <http:// journals.cambridge.org/action/displayAbstract?fromPage $=$ online \&aid $=793216 \&$ fulltextType $=$ RA\&fileId $=S 1478061505000204>$. Acesso em: 07 jan. 2010. doi: 10.1079/ECP200565.

YONEZAWA, L.A. et al. Exame eletrocardiográfico em equinos da raça Puro Sangue Árabe submetidos ao exercício em esteira de alta velocidade e à suplementação com vitamina E. Archives of Veterinary Science, v.14, n.3, p.134-142, 2009. Disponível em: $\quad<$ http://ojs.c3sl.ufpr.br/ojs2/index.php/veterinary/article/ view/15839/11381>. Acesso em: 07 jan. 2011.

YONEZAWA, L.A. et al. Malondialdeído e troponina I cardíaca em equinos da raça Puro Sangue Árabe submetidos ao exercício e à suplementação com vitamina E. Ciência Rural, v.40, n.6, p.13211326, 2010a. Disponível em: <http://www.scielo.br/pdf/cr/v40n6/ a613cr2968.pdf>. Acesso em: 07 jan. 2011. doi: 10.1590/S010384782009005000227

YONEZAWA, L.A. et al. Marcadores cardíacos na medicina veterinária. Ciência Rural, v.40, n.1,p.222-230,2010b. Disponível em: <http://www.scielo.br/pdf/cr/v40n1/a397cr1068.pdf >. Acesso em: 07 jan. 2011. doi: 10.1590/S0103-84782009005000227. 